\title{
La descentralización productiva en Costa Rica
}

\section{Marco Durante Calvo}

Abogado litigante. Licenciado en Derecho por la Universidad de Costa Rica. Magister en Derecho del Trabajo y Seguridad Social por la UNED. Master en Empleo, Relaciones Laborales y Diálogo Social por la Universidad Castilla-La Mancha. Profesor universitario. Correo electrónico: mdurante@bdsasesores.com

Recibido: Enero 2015 • Aceptado: Febrero 2015

\section{RESUMEN}

El objetivo de este estudio es analizar la forma en que la jurisprudencia de Costa Rica ha reglado las distintas formas de descentralización: trabajo autónomo, subcontratación y suministro de mano de obra temporal, y presentar una propuesta de reforma al actual Código de Trabajo de Costa Rica para incorporarle normas más específicas a esas realidades.

Palabras clave: Descentralización productiva, grupos de interés económico, trabajador autónomo, subcontratación, mano de obra temporal.

\section{ABSTRACT}

The objective of this study is to analyze the way in which Costa Rica's jurisprudence has regulated the various forms of decentralization: -independent work, outsourcing and temporary labor supply-and submit a proposal to reform the current Labour Law of Costa Rica to incorporate more specific rules to these realities.

Key words: productive decentralization, groups of self-employed worker, subcontracting, temporary labor and economic interest.

\section{Introducción}

A pesar de que las distintas legislaciones laborales reconocen la presunción favorable a la duración indefinida del trabajo subordinado, lo cierto es que en la práctica estas formas de contratación son cada vez menos comunes. El mercado ha comenzado a buscar nuevas formas de contratación, donde cada vez es más común descentralizar ciertas labores y dejar en un número reducido los trabajadores contratados. En palabras del profesor Umberto Romagnoli, si antes era retórico decir que los nuevos contratados entraban a formar parte de una gran familia y estaban invitados a compartir l'esprit maison, ahora es realista afirmar que se sienten como las hojas de un árbol en otoño (Romagnoli, 2007)

El problema es de fácil entendimiento: la antinomia entre la regulación y flexibilización sigue vigente; esta vez la discusión se centra en la regulación de los servicios que las empresas descentralizan y trasladan a terceros para concentrarse en su actividad principal. En este caso, se trata de aquellas actividades que la empresa requiere, pero que no forman parte de su actividad principal, o bien, la prestación de ciertos servicios que la empresa necesita, pero de forma temporal.

Algunas legislaciones laborales en Europa, como en Latinoamérica ya han dictado sus propias normas para resolver los posibles conflictos 
que este fenómeno de la descentralización puede conllevar. Sin embargo, en Costa Rica hasta el momento no se cuenta con normativa expresa que defina, delimite y regule de manera expresa y eficaz, las distintas formas de descentralización que hoy operan en el mercado costarricense.

El objetivo de este estudio es analizar la forma en que la jurisprudencia de Costa Rica ha reglado las distintas formas de descentralización: trabajo autónomo, subcontratación y suministro de mano de obra temporal, y presentar una propuesta de reforma al actual Código de Trabajo de Costa Rica para incorporar, al heptagésimo código costarricense, normas más específicas, que definitivamente no previó el legislador de 1943 por tratarse de formas de contratación ajenas a la realidad de aquel entonces.

\section{La descentralización del trabajo como nuevo modelo de producción}

En modelos de producción industrial (sobre los cuales el Derecho Laboral elaboró sus bases y normas tradicionales) el patrono era quien se beneficiaba directamente con el trabajo prestado por el trabajador, porque la empresa, tomando como símbolo el modelo fordista, era exitosa en la medida en que lograba concentrar en una sola estructura en un solo sitio todas las etapas del proceso productivo.

Sin embargo, actualmente este modelo de producción en las empresas modernas es cada vez más escaso y cuestionado, debido a que las estrategias empresariales están orientadas hacia la especialización y descentralización; con ello, el concepto de gran empresa, de estructura vertical, consolidada sobre la base de la subordinación, se ha ido sustituyendo por el desarrollo de una red de unidades autónomas y semiautónomas de coordinación, donde la jerarquía da paso a nuevas formas de relación contractual horizontal y, por consiguiente, las distintas legislaciones laborales entran en crisis, ante la falta de normas específicas que regulen esta nueva condición del mercado.

El interés de las empresas de descentralizar cada vez más algunos o la mayoría de sus procesos, como bien lo expone la autora Magdalena Echeverría Tortello (2009), tiene un mayor auge con el desarrollo de las nuevas tecnologías de comunicación y producción. Este permitió que el espacio físico, la ubicación y fortaleza de la producción fuera perdiendo importancia, para que la empresa, de la mano de los nuevos recursos informáticos, se beneficiara de nuevas formas de localización, centralización y control. Lo anterior, coincide con el interés de dichas empresas de huir de la producción para concentrarse en la comercialización; es decir, preocuparse por crear una marca en vez de producir.

Esta posición, expuesta por la autora Naomi Klein, en su libro No logo, advierte que a partir de la década de los ochenta, las fábricas más poderosas del mundo, impulsadas por la recesión de los años anteriores, se dieron cuenta de que padecían de inflación (eran demasiado grandes, demasiados empleados, demasiadas cosas) y que, consecuentemente, el proceso de producción no era el camino al éxito, sino que la producción era un aspecto secundario en sus operaciones y que gracias a la liberalización del comercio estaban en condiciones de trasladar la producción a contratistas y dedicarse ellos a lo más importante, producir y fortalecer la imagen de sus marcas.

\section{La descentralización en Costa Rica}

Para iniciar se debe señalar que en Costa Rica aún sigue vigente el Código de Trabajo de 1943 y que las reformas que hasta la fecha ha sufrido este código han sido superficiales.

Como es de esperarse la realidad social sobre la que fue aprobado el Código de Trabajo costarricense fue muy distinta de la actual. En ese momento las relaciones obrero patronales eran predominantemente agrícolas, con una industria incipiente y un comercio que alcanzaba apenas para cubrir las necesidades de las poblaciones concentradas en las provincias y cabeceras de cantones más desarrollados.

En ese contexto, ni el más visionario de los legisladores podía imaginar que debía pensarse en otros actores de la relación laboral distintos al patrono y al trabajador. A lo sumo, se pensó 
en la actividad de un intermediario, pero hasta ahí. Era impensable prever la aparición de figuras como las subcontraciones o las empresas suministradoras de trabajo temporal. Por eso es que hoy, casi siete décadas después, con el mismo Código de Trabajo y con sus pocas reformas, es que sería iluso esperar un escenario alentador de regulación sobre las nuevas formas de descentralización productiva.

Tal como se evidenciará en las próximas líneas, la jurisprudencia laboral ha tenido que asumir la responsabilidad de proveer de ciertos lineamientos a la sociedad que día con día utiliza distintas formas de descentralización por razones de negocio, de competitividad, pero sin un marco legal idóneo.

\section{El trabajador autónomo}

El Código de Trabajo costarricense define al trabajador de la siguiente manera:

Artículo 4: Trabajador es toda persona física que presta a otra $u$ otras sus servicios materiales, intelectuales o de ambos géneros en virtud de un contrato de trabajo expreso o implícito, verbal o escrito, individual o colectivo

Para complementar lo anterior, el numeral 18 del mismo texto legal establece lo que debe entenderse por contrato individual de trabajo.

Artículo 18: Contrato individual de trabajo, sea cual fuere su denominación, es todo aquel en que una persona se obliga a prestar a otras sus servicios o a ejecutarle una obra, bajo la dependencia permanente y dirección inmediata o delegada de ésta, y por una remuneración de cualquier clase o forma.

Se presume la existencia de este contrato entre el trabajador que presta sus servicios y la persona que los recibe.

Como puede observarse, estas disposiciones se limitan al trabajador por cuenta ajena o al trabajador subordinado. Se deja por fuera al trabajador autónomo, el cual en Costa Rica ha sido una figura sin regulación expresa extraída del arrendamiento de servicios del Código Civil, teniendo la jurisprudencia laboral que dar algunos lineamientos para reconocer cuándo hay trabajo autónomo y cuándo hay trabajo subordinado.

En este sentido, Costa Rica tomó el equívoco camino de la mayoría de las legislaciones laborales que no regularon la figura del trabajo autónomo, sino que simplemente se concentraron en el trabajo subordinado y, consecuentemente, trabajo autónomo fue residual y sin regulación expresa, como por ejemplo lo tiene hoy España. El riesgo de esto es que el número de trabajadores autónomos va creciendo cada vez más; de ahí la importancia de dotar de una regulación expresa a esta figura.

La única norma expresa en legislación en estudio para regular la figura del trabajador autónomo se encuentra en el Reglamento para la Afiliación de Trabajadores Independientes de la Caja Costarricense de Seguro Social. El artículo 1 de dicho reglamento establece que la cobertura de la seguridad social y el ingreso a esta son obligatorias para todos los trabajadores independientes manuales o intelectuales que desarrollen por cuenta propia algún tipo de actividad generadora de ingresos.

A partir de esta ausencia normativa, la jurisprudencia se ha encargado de definir y delimitar la figura del trabajador autónomo. Así por ejemplo, la Sala Segunda de la Corte Suprema de Justicia -máxima autoridad en materia laboral en Costa Rica- en una sentencia del 2012 (1149-2010 de 12 de agosto), con gran claridad hace un análisis de las características del trabajo subordinado y las diferencias con el trabajo autónomo estableciendo que, para determinar si un contrato tiene naturaleza laboral, debe atenderse a las regulaciones establecidas en el numeral 18 del Código de Trabajo, del cual se deduce que con independencia del nombre que se le dé, existe un contrato de trabajo cuando una persona se obliga a prestar sus servicios o a ejecutar una obra a favor de otra u otras personas, bajo su dependencia permanente y dirección inmediata o delegada y por una remuneración, de cualquier clase o forma. 
Por lo general, tal subordinación o dependencia es el elemento fundamental para poder determinar si se está o no en presencia de una relación laboral. Debe apuntarse que, al realizar el análisis de asuntos como el que se conoce, se tiene que tomar en cuenta el principio de la primacía de la realidad, en el cual cuentan antes y preferentemente las condiciones reales que se hayan presentado, las cuales se superponen a los hechos que consten documentalmente, desde el punto de vista jurídico.

La misma jurisprudencia señala que en algunas ocasiones es difícil diferenciar la existencia de un verdadero contrato de trabajo. Esa dificultad se exacerba con el proceso de relativización de la figura de la subordinación, pues, en gran cantidad de casos, la noción de dependencia no permite abarcar la diversidad de formas que reviste el trabajo por cuenta ajena, donde en muchas ocasiones las labores se desarrollan por cuenta propia, en cuanto a la forma de organizar su trabajo, pero por cuenta ajena en cuanto al ámbito directivo y disciplinario. Le corresponde entonces al operador jurídico determinar, en cada caso concreto, si se está o no en presencia de una relación laboral. ${ }^{1}$

Sobre el trabajo autónomo, la Sala Segunda, en la misma sentencia, opta por reconocer los criterios esbozados en el informe presentado en la 91 Conferencia de la OIT del año 2003, para diferenciar un trabajador dependiente de uno

1. Existen similares pronunciamientos de la Sala Segunda sobre este tema. Sin embargo, para no hacer muy extenso el presente trabajo, me limito a solamente hacer referencia de ellos: Resolución número 2010-000825. San José, a las quince horas y diez minutos del diez de junio de dos mil diez; Resolución número 2010-000964. San José, a las catorce horas y cincuenta y dos minutos del treinta de junio de dos mil diez; Resolución número 2010-0001298. San José, a las diez horas y cuarenta minutos del dieciséis de setiembre de dos mil diez; Resolución número 2010-0001438. San José, a las nueve horas y treinta minutos del tres de noviembre de dos mil diez; Resolución número 2010-0001554. San José, a las diez horas y veintidós minutos del veinticuatro de noviembre de dos mil diez. autónomo y enlista las características de cada una de las formas de contratación:

a. es propietario de su propio negocio;

b. está expuesto a riesgos financieros por el hecho de que debe soportar el costo de rehacer todo trabajo mal hecho o de inferior calidad;

c. asume la responsabilidad por las inversiones y la gestión de la empresa;

d. se beneficia pecuniariamente de la bondad de la gestión, programación y correcta realización de los trabajos encomendados;

e. ejerce el control sobre los trabajos que hay que realizar y sobre cuándo y cómo se llevan a cabo y determinar si debe o no intervenir personalmente en el cometido;

f. tiene la libertad de contratar personal, con arreglo a sus condiciones, para realizar las labores a las que se ha comprometido;

g. puede ejecutar trabajos o servicios para más de una persona simultáneamente;

h. proporciona los materiales necesarios para realizar el trabajo;

i. proporciona el equipo y las máquinas necesarios para desarrollar el trabajo;

j. dispone de locales fijos donde funciona su razón social;

k. calcula el costo del trabajo y fija el precio;

1. dispone de sus propios contratos de seguro; $\mathrm{y}$,

m. ejerce control sobre las horas de trabajo realizadas para llevar a cabo el cometido.

Estos pronunciamientos constituyen, sin duda alguna, el marco de referencia para determinar las características del trabajo autónomo en Costa Rica. El gran inconveniente es que la jurisprudencia como fuente de derecho no da la certeza jurídica que otorga la ley.

\section{Los Grupos de Interés Económico}

Como es de imaginarse, el Código de Trabajo costarricense no contiene ninguna norma expresa para regular el tema de los grupos de interés económico. Su regulación se limita a definir la figura de patrono como el que contrata y se beneficia 
directamente de los servicios del trabajador, atendiendo al modelo fordista que imperaba al momento de su promulgación.

Artículo 2: Patrono es toda persona física o jurídica, particular o de Derecho Público, que emplea los servicios de otra u otras, en virtud de un contrato de trabajo, expreso o implícito, verbal o escrito, individual o colectivo.

A partir de esta definición es que le ha correspondido a los tribunales laborales elaborar el concepto de grupos de interés económico para determinar responsabilidades conjuntas. Así por ejemplo, en la sentencia 839-2010 del 10 de junio del año 2010, la Sala Segunda volvió a hacer mención de una renombrada sentencia dictada por ésta misma en el año 2000. En esta aclaró que se está en presencia de un grupo de interés económico cuando existe un conjunto de empresas, formal y aparentemente independientes, pero que están recíprocamente entrelazadas, al punto de formar un todo único, complejo pero compacto, en cuanto responde a un mismo interés.

La doctrina laboral ha tratado de establecer los elementos determinantes del grupo de interés económico $\mathrm{y}$, de manera general, ha indicado que los caracteres esenciales del grupo de empresas son la pluralidad de componentes, los cuales están vinculados entre sí y sometidos a un poder de decisión único y, también, la unidad subyacente del grupo, que está dada precisamente por el interés económico común. Esas empresas están entrelazadas mediante relaciones de subordinación o de coordinación; pero, normalmente, el vínculo es de subordinación.

La resolución continúa diciendo que uno de los problemas comunes en el Derecho del Trabajo, derivado de la presencia de las agrupaciones de interés económico, es la identificación del empleador y, en algunos casos, el problema trasciende a la posibilidad real de hacer efectivos los derechos laborales del trabajador. Ante situaciones como esas, que producen una incertidumbre inicial en la identificación del empleador, los autores son coincidentes de que una vez demostrada la existencia del grupo económico, y con base en el principio de primacía de la realidad y del principio protector, se puede responsabilizar a todos por las prestaciones del trabajador.

Incluso, la misma Sala Segunda, el 7 de julio del año 2010 en su resolución 2010-001010, fue más allá de una simple mención de los grupos de interés económico y al igual de como lo han dispuesto otras legislaciones laborales, se refirió a la necesidad de correr el velo social que cubre la actividad del grupo y responsabilizar solidariamente a todos los participantes que figuren en la demanda por los derechos laborales de los trabajadores.

Así las cosas, se puede sostener que la jurisprudencia laboral costarricense hasta el momento ha reconocido que los grupos de interés económico responden a una tendencia de descentralización productiva. Además, en aquellos casos en que el trabajador es sometido o trasladado entre las distintas empresas que forman parte del holding empresarial, todas serían solidariamente responsables ante el incumplimiento de los derechos del trabajador o cualquier otro derivado de un contrato laboral. En la resolución 2010001549 del 24 de noviembre del 2010, la Sala Segunda de la Corte Suprema de Justicia confirma esta posición:

Las partes demandadas muestran disconformidad en cuanto se condenó a ambas empresas, pues medió un grupo de interés económico. En el recurso, los representantes de esas sociedades aducen que se trata de empresas independientes y la única relación existente entre ellas es que la segunda le suministraba personal a la primera y se encargaba de su pago y administración. Tal y como se ha indicado de manera reiterada, la persona que trabaja no está en la obligación legal de identificar con claridad a su empleador. En el caso concreto, la actora demandó a ambas empresas por estimar que laboraba para las dos...

Analizada la forma en que la jurisprudencia de Costa Rica ha abordado el tema de los grupos de interés económico, ahora es necesario abordar cómo se han regulado las figuras de la subcontratación y el suministro de mano de obra temporal, el cual cada día y con mayor 
frecuencia se posiciona y gana terreno en el mercado laboral costarricense frente a la tradicional contratación laboral.

\section{Subcontratación y el suministro de mano de obra temporal}

El Código de Trabajo de Costa Rica no contiene una norma expresa que regule la figura de la subcontratación, y menos aún el suministro de mano de obra temporal. Es más, cuando el tema se ha discutido en los tribunales laborales se han tratado como formas similares de un mismo fenómeno de descentralización. A lo sumo, con lo que se cuenta es con el artículo 4 ya expuesto, así como el artículo 3, que define la figura del intermediario:

Artículo 3.- Intermediario es toda persona que contrata los servicios de otra u otras para que ejecuten algún trabajo en beneficio de un patrono. Este quedará obligado solidariamente por la gestión de aquél para los efectos legales que se derivan del presente Código, de sus Reglamentos y de las disposiciones de previsión social.

Serán considerados como patronos de quienes les trabajen -y no como intermediarios- los que se encarguen, por contrato, de trabajos que ejecuten con capitales propios.

Este artículo ha servido como base para que los tribunales laborales costarricenses regulen las figuras de subcontratación y suministro de mano de obra temporal. Así por ejemplo, en la resolución 2008-161 del 27 de febrero del 2008, la Sala Segunda de la Corte Suprema de Justicia reconoció con reservas la existencia del fenómeno de descentralización productiva, pero advirtió que en aplicación de la legislación laboral se va a presumir la existencia del vínculo laboral entre el trabajador y la empresa que se beneficia de sus servicios. Es decir, salvo prueba en contrario, la máxima autoridad en materia laboral, para resolver casos similares, se va a considerar que existe un vínculo entre el trabajador y la empresa principal o usuaria y será esta última la encargada de demostrar lo contrario. La resolución explica que el fenómeno de la descentralización empresarial, generalmente a través de la externalización o outsourcing, se caracteriza por la obtención de los objetivos productivos de una empresa principal, no por la incorporación de trabajadores a su planilla, sino por la combinación o coordinación de aportaciones parciales llevadas a cabo por empresas auxiliares o por colaboradores externos.

La descentralización productiva se manifiesta así en el encargo a terceros de la realización, bien de partes en operaciones singulares del ciclo productivo de una empresa, bien de aquellas actividades complementarias que no corresponden a dicho ciclo productivo, pero que son indispensables para su marcha ordinaria. Es importante que el iuslaboralista determine si hay o no trabajo subordinado en las distintas actividades económicas, independientemente si son principales o periféricas.

La Sala continúa la sentencia recalcando que el numeral 18 del Código de Trabajo establece una presunción iuris tantum a favor de la laboralidad de la relación de quien presta sus servicios y la persona que los recibe. En aplicación del artículo 414 del Código Procesal Civil, a tenor de lo dispuesto en el numeral 452 del de Trabajo, toda presunción legal exime a la parte que la alegue de la obligación de demostrar el hecho reputado como cierto en virtud de la misma. No obstante, se obliga a quien la invoque a demostrar los hechos que le sirven de base, a saber, la prestación personal de los servicios.

Finalmente, al realizar el análisis de asuntos como el que se conoce, debe tenerse en cuenta el principio de la primacía de la realidad, cuya aplicación está implícita en el mencionado artículo 18. Por esa razón, el contrato de trabajo ha sido llamado "contrato-realidad" dado que, tanto legal como doctrinaria y jurisprudencialmente se ha aceptado, de forma pacífica, que la relación de trabajo está definida por las circunstancias reales que se den en la práctica.

Esta posición de la Sala Segunda de trasladar a la empresa principal o usuaria la carga probatoria de demostrar que no hay tal vínculo de relación laboral, ha sido expuesta en otras 
sentencias del mismo año 2008. Tal es el caso de la resolución 2008-000202, la cual dicta que la entidad beneficiada con la fuerza laboral del trabajador, que niegue su carácter de empleadora es quien debe acreditar -sin lugar a dudas- que en realidad no lo es.

A pesar de la apariencia que los contratantes hayan pretendido dar a la relación, en aplicación del principio de primacía de la realidad, el juez está llamado a analizar sus particularidades, a efecto de dilucidar si lo pactado pretendía disimular la existencia de un contrato de trabajo, o si, por el contrario, legítimamente, el vínculo jurídico que existió entre las partes no tuvo esa naturaleza. ${ }^{2}$

Finalmente, al igual a como lo han expuesto otras legislaciones, el juez laboral costarricense ha echado mano de la prueba indiciaria para reconocer el verdadero responsable en los contratos de subcontratación (comúnmente conocidos en Costa Rica como contratos de outsourcing), y los contratos de suministro de mano de obra temporal. La sentencia 863-2010 dice, en relación a los contratos de subcontratación, que por su manera de operar han hecho confuso para el trabajador el reclamo respecto a sus derechos laborales, al no tener conciencia plena de quién es su empleador.

Esta figura debe de examinarse con cuidado, ya que con independencia de la denominación que las partes pudieron haber dado a la contratación, pueden entrañar un subterfugio para enmascarar una relación de trabajo. De esta manera, el aplicador del derecho deberá recurrir a un sistema indiciario para establecer si en la praxis se presentan los elementos esenciales de un contrato laboral.

2. Sobre la obligación de la empresa usuaria de demostrar que la naturaleza jurídica era diferente a la laboral, véanse también las resoluciones de la misma Sala Segunda número 2009-345. San José, a las nueve horas treinta minutos del seis de mayo de 2009. Resolución número 2009-822. San José, a las once horas cinco minutos del veintiséis de agosto de dos mil nueve; Resolución número 2010-462. San José, a las diez horas treinta minutos del veintiséis de marzo de dos mil diez.
Hasta este punto ha avanzado la jurisprudencia laboral costarricense. Si se hace un recuento, se comprueba que los tribunales han resuelto de buena forma los llamados grupos de interés económico y han logrado dar la pauta sobre cuáles son las características del trabajador autónomo. Sin embargo, su incidencia sobre la subcontratación y principalmente sobre el contrato de suministro de mano de obra temporal ha sido escasa. A lo sumo, lo que se puede concluir actualmente, es que si la subcontratación o el contrato de suministro de mano de obra temporal se realiza entre empresas que pertenecen a un mismo grupo de interés económico, los tribunales de Costa Rica imputarían una responsabilidad solidaria a todas las empresas del grupo involucradas.

Pero ¿qué sucede en aquellos casos (que son la mayoría) de empresas independientes donde no hay de por medio la figura del holding empresarial, sino un simple contrato mercantil propio de las nuevas tendencias descentralizadoras del mercado laboral? Para estos casos, los tribunales han determinado que se presume la relación laboral entre la empresa principal y el trabajador, y que será esta última la que tendrá que demostrar que entre ésta y el trabajador existe una forma de ajena al contrato de trabajo, y caso contrario será responsable ante el trabajador y las autoridades correspondientes.

El gran problema -para el cual no se ha encontrado una respuesta satisfactoria y de ahí la necesidad de una reforma laboral- sucede cuando la empresa usuaria logre demostrar fehacientemente la subcontratación (o el contrato de outsourcing como comúnmente se le denomina en Costa Rica) o el contrato de suministro de mano de obra temporal que lo relevaría de cualquier responsabilidad, pero, la empresa subcontratista o suministradora del servicio no le hace frente a las responsabilidades que ha adquirido con el trabajador o bien con la seguridad social. Para estos casos, hay una evidente desprotección en perjuicio del trabajador, de la seguridad social, y hasta de la misma empresa principal o usuaria. Esto debido a que en cualquier momento, un juez laboral le puede imputar toda la responsabilidad, 
a pesar de estar haciendo uso de una figura legalmente permitida.

Es precisamente por este panorama que en Costa Rica se debe promover una reforma al Código de Trabajo para incluir ciertas normas que regulen las figuras de grupo de interés económico, la subcontratación y el suministro de mano de obra temporal. Estas normas, sin duda, aportarían seguridad jurídica y traerían tranquilidad en el mercado laboral costarricense.

\section{Propuesta de reforma en Costa Rica para regular la descentralización productiva}

Respecto a la subcontratación y el suministro de mano de obra temporal, sería suficiente con incluir en el Código de Trabajo algunas nuevas disposiciones en los artículos 3 y 69. Esta medida aportaría, junto con la tradicional regulación del intermediario, a definir las figuras de la subcontratación de la subcontratación (contratas y subcontratas de la legislación española) y la figura del suministro de mano de obra temporal. De manera que, en lo sucesivo dicho artículo disponga lo siguiente:

Artículo 3: Intermediario es toda persona que contrata los servicios de otra u otras para que ejecuten algún trabajo en beneficio de un patrono.

Este quedará obligado solidariamente por la gestión de aquél para los efectos legales que se deriven del presente Código, de sus Reglamentos y de las disposiciones de previsión social.

Serán considerados como patronos de quienes trabajen -y no como intermediarios-los que se encarguen, por contrato, de trabajos que ejecuten con capitales propios.

Subcontratista es toda persona que se encarga de ejecutar obras o servicios, por cuenta y riesgo propio y con trabajadores bajo su dependencia para una tercera persona física o jurídica denominada empresa principal en razón de un acuerdo contractual, siempre que dichos servicios formen parte de la actividad normal de la empresa principal.
Empresa suministradora de mano de obra temporal es la que contrata personal a nombre y cuenta propia para que en razón de un acuerdo contractual, presten servicios a una tercera persona fisica o jurídica, denominada empresa usuaria, quien determinará sus tareas y supervisará su ejecución. (en rojo la nueva parte a agregarse vía reforma)

Por otra parte, y con el objetivo de determinar el nivel de responsabilidad que podrían tener las empresas subcontratistas, las suministradoras de mano de obra temporal, así como las empresas principales o usuarias, se podría incluir nuevas obligaciones a las hasta ahora señaladas en el artículo 69 del Código de Trabajo. De ahí que, con dos nuevos incisos sea posible incrustar las figuras del derecho de información, el derecho de retención, el pago en subrogración, así como los niveles de responsabilidad solidaria o subsidiaria correspondientes, como lo tienen las otras legislaciones laborales estudiadas:

Artículo 69: Fuera de las contenidas en otros artículos de este código, en sus Reglamentos y en sus leyes supletorias o conexas, son obligaciones de los patronos:

a) Enviar dentro de los primeros quince días de los meses de enero y julio de cada año al Ministerio de Trabajo y de Seguridad Social, directamente o por medio de las autoridades de trabajo o politicas del lugar donde se encuentre su negocio, industria o empresa, un informe que por lo menos deberá contener:

1. Egresos totales que hubiere tenido por concepto de salarios durante el semestre anterior, con la debida separación de las salidas por trabajos ordinarios y extraordinarios, $y$

2. Nombre y apellido de sus trabajadores, con expresión de la edad aproximada, nacionalidad, sexo, ocupación y número de días que hubiere trabajado cada uno junto con el salario que individualmente les haya correspondido durante ese periodo, excepto en cuanto a los trabajadores que ocasionalmente se utilicen en las explotaciones agrícolas para la recolección de cosechas, paleas, macheteas y demás trabajos agrícolas que no tengan carácter permanente. 
(Reformado el aparte 2) por el artículo 1o de la Ley 25 de 17 de noviembre de 1944 dictada por el Congreso Constitucional de la República de Costa Rica).

En caso de renuencia en el suministro de dichos datos, el patrono será sancionado con multa de cincuenta a cien colones; y si se tratare de adulteración maliciosa de los mismos, las autoridades represivas le impondrán la pena que expresa el artículo 426 del Código Penal. Esta disposición no comprende al servicio doméstico;

(Nota: La obligación a cargo de los patronos estipulada en este inciso fue suspendida por Ley No 212 de 8 de octubre de 1948, art.1o)

b) Preferir, en igualdad de circunstancias, a los costarricenses sobre quienes no lo son, y a los que les hayan servido bien con anterioridad respecto de quienes no estén en ese caso;

c) Guardar a los trabajadores la debida consideración, absteniéndose de maltrato de palabra o de obra;

d) Dar oportunamente a los trabajadores los útiles, instrumentos y materiales necesarios para ejecutar el trabajo convenido, debiendo suministrarlos de buena calidad y reponerles tan luego como dejen de ser eficientes, siempre que el patrono haya consentido en que aquéllos no usen herramienta propia;

e) Proporcionar local seguro para la guarda de los instrumentos y útiles del trabajador, cuando éstos necesariamente deban permanecer en el lugar donde se presten los servicios. En tal caso, el registro de herramientas deberá hacerse siempre que el trabajador lo solicite;

f) Permitir la inspección y vigilancia que las autoridades de trabajo practiquen en su empresa para cerciorarse del cumplimiento de las disposiciones del presente Código, de sus Reglamentos y de sus leyes conexas, y darles los informes indispensables que con ese objeto soliciten. Los patronos podrán exigir a estas autoridades que les muestren sus respectivas credenciales;

g) Pagar al trabajador el salario correspondiente al tiempo que éste pierda cuando se vea imposibilitado para trabajar por culpa del patrono; h) En los lugares donde existen enfermedades tropicales o endémicas, proporcionar a los trabajadores no protegidos con el seguro correspondiente de la Caja Costarricense de Seguro Social, los medicamentos que determine la autoridad sanitaria respectiva;

i) Proporcionar a los trabajadores campesinos que tengan tres o más meses de trabajo continuo, la leña indispensable para su consumo doméstico, siempre que la finca de que se trate la produzca en cantidad superior a la que el patrono necesite para la atención normal de su respectiva empresa; y permitir que todos los trabajadores tomen de las presas, estanques, fuentes u ojos de agua, la que necesiten para sus usos domésticos y los de sus animales, si los tuvieren. A efecto de cumplir la primera obligación quedará a elección del patrono dar la leña cortada o indicar a los trabajadores campesinos dónde pueden cortarla y con qué cuidados deben hacerlo, a fin de evitar daños en las personas, cultivos o árboles.

Estos suministros serán gratuitos y no podrán ser deducidos del salario ni tomados en cuenta para la fijación del salario mínimo;

j) Conceder a los trabajadores el tiempo necesario, sin reducción de salario, para el ejercicio del voto en las elecciones populares y consultas populares bajo la modalidad de referéndum. (Reformado por artículo 35 de la Ley 8492 de 9 de marzo del 2006)

k) Deducir del salario del trabajador, las cuotas que éste se haya comprometido a pagar a la Cooperativa o al Sindicato, en concepto de aceptación y durante el tiempo que a aquélla o a éste pertenezca y con el consentimiento del interesado, siempre que lo solicite la respectiva organización social, legalmente constituida. Deducir asimismo, las cuotas que el trabajador se haya comprometido a pagar a las instituciones de crédito, legalmente constituidas, que se rijan por los mismos principios de las cooperativas, en concepto de préstamos o contratos de ahorro y crédito para la adquisición de vivienda propia, con la debida autorización del interesado y a solicitud de la institución respectiva.

La Cooperativa, Sindicato o institución de crédito que demande la retención respectiva, deberá comprobar su personería y que las cuotas cuyo descuento pide, son las autorizadas por los estatutos o contratos respectivos. 
l) Los subcontratistas o las empresas suministradoras de mano de obra indicadas en el artículo 3 estarán obligadas a dar y exhibir información a las personas físicas o jurídicas que los contrataren sobre el monto y estado de cumplimiento de las obligaciones laborales, cuotas obrero patronales, póliza de riesgos del trabajo, permisos migratorios, cuando éste así se lo solicitare. En caso que el subcontratista o la empresa suministradora de mano de obra no acredite la información, queda facultada la empresa usuaria a retener de las obligaciones que tenga con aquél o aquéllos el monto correspondiente. Quien ejerciere dicha facultad, tendrá la obligación de cancelar con los montos retenidos a los trabajadores o a los entes de seguridad social o riesgos del trabajo.

Adicionalmente, la empresa usuaria podrá hacer un pago en subrogación a favor del trabajador o los entes de seguridad social o riesgos del trabajo.

1l) La empresa usuaria que ejerza la facultad descrita en el inciso anterior, responderá subsidiariamente de las obligaciones del subcontratista o la empresa de suministro de mano de obra temporal. Cuando no ejerza esta facultad, será solidariamente responsable con la empresa contratada por dichas obligaciones. Las obligaciones quedan limitadas al período de subcontratación o suministro de mano de obra (en rojo los dos incisos que se agregarian al actual artículo 69 del Código de Trabajo).

En lo que se refiere a la regulación del trabajo autónomo, del cual en Costa Rica tampoco existe disposición expresa alguna (y del que no se presenta una propuesta de regulación, por no ser objeto de esta investigación), se considera que la reforma no es prudente hacerla en el Código de Trabajo, sino que dada su magnitud, debería hacerse de la misma manera que sucedió en España. Es decir, con la aprobación de todo un estatuto que defina las características del trabajador autónomo e incluso, haga las diferencias entre el trabajador autónomo ordinario y el trabajador autónomo dependiente económicamente, con el fin de dar protección a este grupo de trabajadores, que aunque se alejó del trabajo subordinado, por sus condiciones particulares requiere de una protección distinta y especial.

\section{Conclusiones}

La descentralización productiva es el resultado de las tendencias del mercado laboral de las últimas décadas y su conceptualización dista en mucho de la tradicional forma de producción fordista centralista, sobre la cual se edificaron los códigos de trabajo de Iberoamérica.

Mientras que en otras legislaciones laborales reaccionaron rápidamente ante esta nueva tendencia y realizaron las reformas necesarias a sus respectivas legislaciones para hacer frente a estos nuevos modelos productivos, Costa Rica se quedó atrás con el aún vigente Código de Trabajo de 1943. Se ha trasladado a los jueces laborales la responsabilidad de regular el impacto de estas novedosas formas de contratación en red -cada vez más horizontales que verticales- y los posibles conflictos que su aplicación diaria puedan llegar a tener.

El problema de esta delegación es que el juez está limitado a aplicar las leyes vigentes, no puede ir más allá de lo que la legislación dispone y por ello, los lineamientos que ha señalado han sido insuficientes para regular de forma segura y satisfactoria estas nuevas figuras triangulares donde participa el trabajador.

Tomando en cuenta la esencia de la idiosincrasia del costarricense, es que esta propuesta de reforma legislativa no requiere de la aprobación de una ley especial. Por el contrario, se plantea dentro del mismo Código de Trabajo, sin variar la numeración hasta ahora existente, y con simplemente incluir algunos párrafos a artículos ya vigentes.

\section{Referencias bibliográficas}

Costa Rica. Reglamento para la Afiliación de Trabajadores Independientes de la Caja Costarricense de Seguro Social de Costa Rica del 5 de agosto de 2004.

Costa Rica. Sala Segunda de la Corte Suprema de Justicia. Resolución 2008-161, de las diez horas veinte minutos del 27 de febrero del 2008.

Costa Rica. Sala Segunda de la Corte Suprema de Justicia. Resolución 2008-000202, de las ocho horas y treinta minutos del siete de marzo del 2008. 
Costa Rica. Sala Segunda de la Corte Suprema de Justicia. Sentencia 839-2010 del 10 de junio.

Costa Rica. Sala Segunda de la Corte Suprema de Justicia. Resolución 2010-000863, de las nueve horas diez minutos del 16 de junio del 2010.

Costa Rica. Sala Segunda de la Corte Suprema de Justicia. Resolución 2010-001010, del siete de julio.

Costa Rica. Sala Segunda de la Corte Suprema de Justicia. Sentencia 1149-2010 de 12 de agosto.
Echeverría Tortello, Magdalena (2010). La historia inconclusa de la subcontratación y el relato de los trabajadores. Santiago: Dirección del Trabajo.

Klein, Naomi (2001). No logo. El poder de las marcas. Buenos Aires: Paidós.

Romagnoli, Umberto (2007). Lección inaugural (José Luis López Bulla y Antonio Baylos, trads.). Curso italo-latinoamericano para Expertos en los Problemas Laborales. OIT, Universidad de Bolonia y Universidad de Castilla La Mancha. Bolonia. 
